\title{
The present situation and Countermeasures of teachers' psychological health in Higher Vocational Colleges
}

\section{Zhang Yuanyuan}

\author{
Dalian Vocational \& Technical College, Liaoning Dalian, 116035
}

\begin{abstract}
Key words: mental health; meaning and function; problem; suggestion
\end{abstract}
\begin{abstract}
Nowadays, with the development of economy, the progress of human civilization, social construction, the education sector has made great progress, more and more schools have been built, more and more parents pay attention to children's education, more and more students are assigned more and more courses. Whether or not the key to the study of the students lies in whether the teacher is well educated. Therefore, in the stage of the students, the physical and mental health of the students depends on the quality of the teachers. Some teachers psychological quality is good, it will give students a positive role, some teachers psychological quality is not suitable, it will bring negative effects to students. The teacher is the leader of the students, only the teacher has a sound psychological quality, will give the students to take the lead role, let the students better to learn, to create, to stimulate their potential. Therefore, this paper expounds the factors affecting the psychological health of teachers in higher vocational colleges, the significance and function of their mental health problems, aiming at these problems put forward suggestions on the present situation and Countermeasures on Teachers' psychological health problems of Higher Vocational colleges.

Research shows that nearly half of the teachers' psychological health is affected by different degree: $31.51 \%$ teachers have mild mental disorders, $12.37 \%$ of the teachers have moderate mental disorder, and $21 \%$ of the teachers has a mental illness, accounted for the largest proportion of the $69 \%$ teachers feel great psychological pressure, appear envy mood, anxiety is high. The survey found that the main symptoms of psychosomatic problems of teachers mainly manifested as depression, lethargy, anxiety, worry, there is no reason for a sense of unease, unable to sleep. These problems affect the mental health of teachers, so that teachers in the teaching of the class time, and constantly improve themselves, in order to themselves, but also for students to learn better.[1]
\end{abstract}

\section{Introduction}

Teachers' job stress, which is the pressure of teachers' occupation, is the pressure of the teachers' demands, expectations and responsibilities.

It can be seen that the teacher's pressure is very large, not only in the classroom there is a lot of pressure on students, if education is not a good student, also have a lot of pressure in the class, in life will encounter a lot of problems. Job stress is one of the most important factors that affect the mental health of teachers.

As we all know, the classroom this occupation is an occupation very hard, teachers should not only have to pay the mental labor and physical labor, not only pay attention to each student's physical and mental health and learning in the classroom, but also in the class to students correcting homework, let the students learn more content, continuous progress.

Therefore, factors influencing the mental health of teachers is also a burden is too heavy, let the teachers have no time to breathe, teachers will lose the interest in teaching, it will dampen their 
enthusiasm, so students will not Study hard, also do not understand the hard work of teachers, over time, student grades, teaching quality the teacher will fall.

Turn around the students during the day, the class is not finished, late night to prepare lessons to change the job, study all by squeezing time; tense morning, the battle of the afternoon, tired of the evening, not work Sunday." This is a faithful portrayal of many teachers' work! Sue Home Linsky once said: "teachers do not have free time, is a real threat to the school."

These examples and famous quotes indicate a problem, if the teacher is not without their own spare time, will lack the spirit of self-expression, not always in class, the teacher, never free, this is a kind of their own is not responsible for, is not responsible for the school teachers, students of the threat to the classroom always living under intense pressure.

The student is a teacher of teachers only carrier, mental health, will bring to the mental health of students, but in many cases, students are always with teachers naysayers, it will affect the mood of teachers, so that teachers have no good mood, will be scores of students, the psychological impact is not good, therefore, with the students of teachers it is also one of the important factors affecting teachers' psychological health.[2]

\section{The significance and role of teachers' mental health}

The teacher is the leader of the students. Only the teacher's mental health is mature, will let the students in the teacher's influence of continuous progress. Students are the primary learning, but the teacher is to continue learning, teachers' psychological health for the students, to improve student achievement, is conducive to the mental health of students, help students to study hard, helps students to stimulate their potential.

For the teachers, the work efficiency is the most important, the students have a good result, will let the teacher have a relatively high working efficiency, on the contrary, if students are very poor, so, the teacher will have a very low work efficiency.

Work efficiency for the teachers, is very important, a good teacher in the daily teaching, improve their teaching methods constantly, make their teaching more interesting, let the students more and more easy to accept.

In the school, in addition to the students, teachers are the most important part, let the students learn better is the teacher's responsibility, let the students to establish a positive psychological quality are the greatest pursuit of teachers.

For schools, teachers' psychological health is conducive to the school towards the positive energy in the direction of development, so that the school had more impact, will have a space for one person in the field of education, for better development of the school, to become a better school.[3]

\section{The characteristics of Higher Vocational College Teachers' mental health}

Be cheerful, open-minded, consistent, be the same outside and inside performance; it must have a correct outlook on life, education, students, teachers, firm confidence, tenacious tireless in teaching others, not arrogant, prosperity, adversity is not pessimistic.

These qualities are essential characteristics, as a teacher a teacher of teachers, not only to strictly restrict the behavior of students, also want to restrict their behavior, regulate their own behavior, develop their individual value.

Everyone has their own circle of friends, everyone has their peculiar friends, so interpersonal communication is an indispensable aspect of teachers. If you know that teachers do not even have 
the courage to communicate with the students, then she would not be a teacher, is not qualified to be a teacher.

As one of the most basic characteristics of a teacher is to have a good, harmonious interpersonal relationship, so that students are willing to communicate with you, to tell you their psychological words, will be a qualified teacher.

As a teacher, a lot of students are taught to you, it brings a lot of pressure on teachers, but as a teacher, to create the uniqueness of learning.

Teachers in the teaching process of continuous learning, continuous progress, continuous creation. According to the student's life, psychological and social characteristics and creative understanding of materials, select the appropriate teaching methods, and teaching design, the use of language, arrangement homework, students can quickly accept the schooling methods emerge in an endless stream of. Let the students continue to learn, unremitting efforts to stimulate their potential, so that students score on a higher level.

The control force is everyone must pay attention to in the process of dealing with people's problems with self-control, will not be in the process of interacting with people in conflict with others; have self-control, will establish a good relationship with others.

Therefore, the establishment of an important feature of teachers' mental health is the teacher's personal control, so that teachers continue to control their emotions, students have enough patience.

\section{Higher vocational college teachers mental health problems}

Now, health is not only refers to the health of the body, but refers to the health of the mind, as a teacher, with a good mental health is the basis. However, there is a big problem now the teachers' psychological health, occupation literacy is a serious problem, teachers do not have good occupation accomplishment, will make the teacher is not responsible for the students, do not pay attention to observe the change of students' psychological health, even if the students' psychological problems, they will not be found.

As a teacher, in fact, there are a lot of psychological pressure, pressure from school to school, teacher education to every student, from the pressure of students, students naughty, Study hard, the pressure from family, teachers and families in the family, they play an important role, they to cook, wash clothes, there are all kinds of chores to do.

These pressures, so that the teacher's psychological pressure is very heavy, so that teachers have a psychological imbalance, it will reduce the quality of education.[4]

According to Maslow's hierarchy of needs theory, everyone has the need for self actualization, and as a teacher, it needs the realization of subjective value.

But because of the knowledge foundation of private vocational students is weak, to learn the basis of poor, learning interest and learning enthusiasm is not high, sometimes students even in a critical and critical attitude to the evaluation of teachers' knowledge level and teaching ability, and self-management ability of many students is poor, it is to increase the pressure of teacher management. Some students even sometimes in dealing with these students, teachers and management methods are the school management attitude differences, leading teachers have doubts, in the tube and tube, tube, no matter how the degree of confusion, seriously dampened the enthusiasm of teachers, increase the teacher's mental burden. For a long time, teachers will lose confidence in the realization of individual value, resulting in a vicious cycle. 


\section{For these problems put forward suggestions}

The teacher must have knowledge of self value, the correct understanding and evaluation of their own, so that their individual healthy personality can be perfect, teachers should take a correct understanding and objective evaluation of yourself and others, and have the right attitude, and generate the appropriate emotional experience, make correct behavioral responses for the emergence of this situation. Teachers should improve their mental health level by cultivating their own personality and improving their character. If there is a bad mood, teachers need to be reasonable and appropriate to vent their unpleasant emotions, so as to enhance their ability to control emotions.[5]

Part of the reason depends on Teachers' income level of mental health of teachers, teachers with high income, it will form a psychological balance, because people know that teachers should pay more attention than other occupation, more time, so if teachers' income is low, teachers' psychological imbalance.

Therefore, in order to the development of teachers' professional, we must properly improve the income of teachers, so that teachers have a fair mind, for students, for teachers, for schools, are the best.

The important factors of the psychological health of teachers depends on the campus environment, the environment can affect a person's mood, the school can organize some activities inside and outside the school, can promote between teachers and teachers, teachers will also help themselves to adjust their mentality, cultivate their cheerful mood. To create a good environment of harmony, from the emotional care, cherish them, take the teacher as the center, to keep people, keep people, keep people feeling "cause, make its value realization, find a sense of belonging, so as to make the classroom devoted work, schools need to stabilize as a teacher key management goal.

Teachers have to pay more energy than others, they need to protect the community, but also the need for school attention, teachers will make efforts to contribute their individual strength.

Therefore, under reasonable conditions, to improve the management system, a fair and reasonable system environment for teachers to create, not only to restrict the behavior of teachers, but also to maintain the interests of teachers, let teachers feel the warmth from the school, there will be more and more pay more attention and efforts.

As a teacher, it is inevitable that there will be psychological barriers, obstacles from the school, barriers from the self, obstacles from students.

If you want to eliminate the psychological barriers of teachers, the classroom to establish a good mental health, it is necessary to communicate with teachers' psychological, and compatible with the teachers' psychological, lack of inclusive teacher and help them correct.[6]

The teacher is the gardener, teachers have a mental health, but also provides a condition for the healthy growth of the students, the school should not only pay attention to students' physical and mental health, but also pay close attention to the psychological health of teachers, so as to improve the teaching level of teachers, so that teachers have a sense of happiness.

\section{References:}

[1]Hu A, Vargas N. Economic consequences of horizontal stratification in postsecondary education: evidence from urban China[J]. Higher Education, 2015, 70(3):337-358.

[2]Wu G, Chen L, Su Y, et al. The influence of psychological stress on the rat temporomandibular joint with the application of countermeasures.[J]. Journal of Surgical Research, 2012, 
178(2):728-736.

[3]Wang G L, Zhang Y Z, Chen Y Q, et al. Investigation of mental health status among Tibetan nursing students in free vocational education programs[J]. Journal of Nursing Administration, 2014.

[4]Barling J, Dupré K E, Kelloway E K. Predicting workplace aggression and violence.[J]. Annual Review of Psychology, 2009, 60(60):671.

[5]3Rd M C, Doran A, Steffian G, et al. Stress-induced deficits in working memory and visuo-constructive abilities in Special Operations soldiers[J]. Biological Psychiatry, 2006, 60(7):722-729.

[6]Geurts S A, Sonnentag S. Recovery as an explanatory mechanism in the relation between acute stress reactions and chronic health impairment.[J]. Scandinavian Journal of Work Environment \& Health, 2006, 32(32):482-492.

About the Author:

Zhang Yuanyuan, (1982.1-), female, Han, from Liaoning Dalian, Master of software engineering, Dalian University of Technology, lecturer, Research direction: Ideological and political education of College Students, Mental health field。

Topic: The present situation and Countermeasures of teachers' psychological health in Higher Vocational Colleges 